\title{
ANEURYSMS OF THE ABDOMINAL AORTA
}

\author{
Charles MarKs, M.D., M.R.C.P., F.R.C.S. \\ Professor of Surgery, Marquette University Medical \\ School, Wisconsin; Surgeon, Milwaukee County \\ General Hospital
}

AN ANEURYSM of the aorta irrespective of its location or its etiology is a serious threat to the patient due to its tendency to enlarge and to the fact that serious complications from rupture, dissection, pressure effects or peripheral embolization from a mural thrombus threaten the life of its victim. The frequency of death from complications has long been known, and Colt in 1927 collected a series of 503 patients with thoracic aortic aneurysms and 121 patients with aneurysms of the abdominal aorta and demonstrated that the average survival of these patients was less than two years from the time of first diagnosis. Similarly, Wright (1956) made a study of 60 patients with abdominal aneurysms and found that only $40 \%$ survived two years from the time of diagnosis whilst all the patients had died within seven years. In a review of 101 cases by Estes (1950), $50 \%$ were dead after three years.

The rapid development of vascular surgery, now permits the resection of an uncomplicated abdominal aortic aneurysm and replacement by graft with a fair degree of safety for the patient. Since the first successful performance of this procedure by Dubost in 1951, the work of DeBakey (1953), Robb (1953), Boyd (1957), and others have helped to standardize the surgical technique as well as to demonstrate the superiority of vascular prostheses over aortic homographs. (Edwards, 1959).

\section{Case Material}

In the ten-month period, October 1963 to July 1964, the surgical service of the Milwaukee County General Hospital admitted 14 patients for resection of abdominal aortic aneurysms. Their ages ranged from 54 years to 89 years with an average age of 74 years. Ten males and four female patients comprised this series.

In eleven of these patients the aortic resections were performed on an elective basis. Abdominal pain or pain in the back was the main presenting feature in these patients, a pulsating abdominal mass being easily felt. Calcification was readily apparent on straight abdominal X-rays in three of these patients. Aortography was utilized in only three of these patients. In one case, aortography was used to determine the state of the ilio-femoral vascular tree. In another, it was performed to relate the upper limit of the aneurysm to the renal arteries in a patient with hypertension in whom renal arter stenosis was suspected, whilst in the third case a aortogram demonstrated a clinically unsuspectef aneurysm in a patient undergoing a vascular study for ilio-femoral occlusive disease. Ten of these patients survived the procedure, were discharged from hospital, and at present all are alive and weyp and being followed in the clinic. The one death wast due to a massive myocardial infarct in an 88-year-ota female which became apparent on the electrocardi $\alpha$. graphic oscilloscope at the completion of the operativie procedure with her death soon after returning to the recovery ward.

Three patients presented as emergency procedur $6 \mathrm{~S}^{\mathrm{S}}$ with rupture of the aneurysm and massive exsanguip ation. The one survival continues to do well, whilso the two deaths were due to myocardial infarctiog 24 hours postoperatively in the one and death from anuria 36 hours postoperatively in the other.

\section{Preoperative Evaluation}

The presence of a palpable pulsatile absీ minal mass with or without back pain 응 abdominal pain makes the diagnosis of aneurysm of the abdominal aorta a fair simple matter. The presence of calcification of the aneurysm is readily apparent on a straigli $X$-ray of the abdomen, (Figure 1) and oftem this will indicate the relationship of the uppers extent of the aneurysm to the renal arteries. This relationship can be further ascertained by the use of intravenous pyelography and, if considered necessary, by aortography. Aortor graphy is not, in our opinion, required routinely, but is utilized to demonstrate the relationshis of the aneurysm to the renal arteries, to evaluate aorto-iliac arteriosclerotic occlusion of peripheral arterial inadequacy and in selected cases of hypertension. For better detail regards ing the patency of the arterial outflow tract is the lower extremity, femoral arteriography ma be further indicated. An X-ray of the chest always performed, and it is important to ex. clude a concomitant supradiaphragmatic an eurysm. It has been our practice to use the percutaneous lumbar route at D11-D12 leve् for aortography.

Evaluation of the coronary cerebral an renal circulations may be necessary, and thus electrocardiography is never omitted and in the presence of myocardial disease, it becomes 


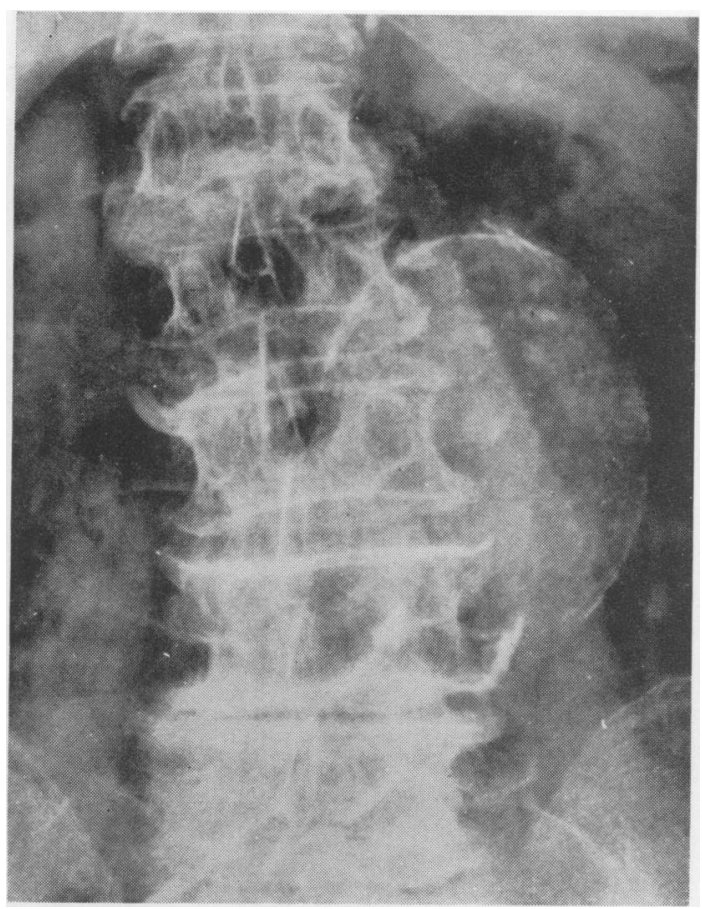

FIG. 1.-Straight X-ray of abdomen demonstrating calcification of aortic aneurysm.

necessary to weigh the risks of cardiac complications against the risk of aneurysmal rupture. In two of our patients with previous myocardial infarction, aortic resection was followed by an uncomplicated convalescence.

Renal function is established by carrying out a full urinalysis, estimation of blood urea and creatinine clearance, intravenous pyelography and, where hypertension is thought to be due to renal artery stenosis, aortography.

Carotid and vertebral arteriography have been performed only where syncopal attacks suggested the possibilty of cerebral arterial impairment.

\section{Preoperative Preparation}

A nasogastric tube is passed and an indwelling urethral catheter permits measurement of urinary output during and immediately after operation. A fall in urinary output to below $30 \mathrm{ml}$. in any one hour prompts our use of low molecular weight dextran and mannitol.

An intravenous infusion via a polythene catheter is arranged in the arm and not the leg as it may become necessary to occlude the inferior vena cava in controlling venous hemorrhage. Five pints of blood should always be cross matched and be readily available, al- though, in several of our patients we used as little as two pints. It is important to replace volumetrically all blood lost to reduce the incidence of operative and postoperative hypotension. A venous catheter provides a constant monitor of venous pressure whilst ten-minute blood pressure readings are taken during the operation. The oscilloscope with an operative electrocardiographic monitor provides immediate information regarding any changes in myocardial status.

\section{Technique}

Even if preoperative studies indicate patency of the iliac and femoral arteries, access to the femoral and on occasion to the popliteal arteries may be necessary. For this reason the entire abdomen and both thighs are prepared and appropriately draped, whilst free access to the feet permits observation of changes in skin color, venous filling or changes in the pedal pulses.

\section{Anesthesia}

All patients have been induced with pentothal and succinylcholine, were intubated and maintained with cyclopropane and oxygen.

\section{Incision}

A long midline incision from xiphoid to pubis, skirting the umbilical cicatrix, provides adequate access for the technical maneuvers required. A careful general abdominal exploration is carried out with special attention being given to the stomach, gallbladder, pancreas and colon. The superior mesenteric and renal arteries are palpated for atherosclerotic plaques. After completion of the aortic resection, and insertion of the graft, we have performed appendicectomy in one case, and in another, cholecystectomy.

After total exteriorization of the small intestine from the abdominal cavity, ready access to the aorta is provided. The retroperitoneal portion of the duodenum is often closely attached to the aorta and careful division of the ligament of Treitz provides a plane of cleavage for its separation. Free exposure of the aorta is attained by dissecting the posterior peritoneum from the anterosuperior surface of the aneurysm, and it is wise to clear that portion of the aorta proximal to the aneurysm so that application of a clamp with provision of proximal control becomes possible at an early phase of the operative procedure in case of inadvertent damage to the aneurysm or to the 


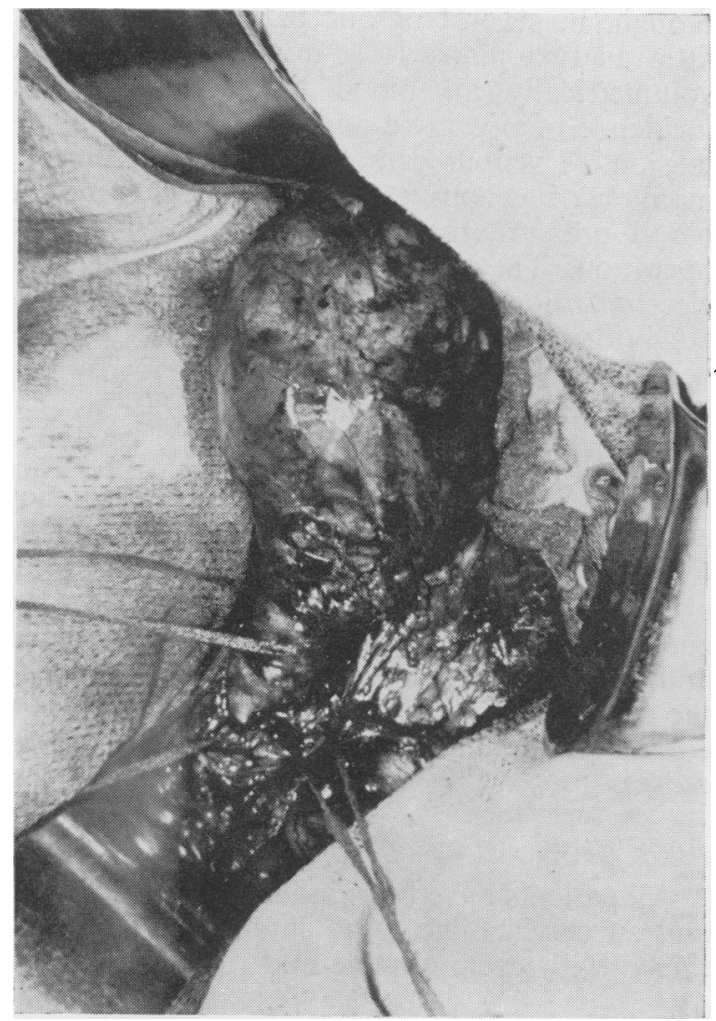

FIG. 2.-Aneurysm of aorta dissected and ready for clamp control and resection.

distal vessels. A distinct anatomical gap between the aorta and inferior vena cava exists at this level providing a safety factor in the dissection (Fig. 2).

Great care needs to be taken not to injure the left renal vein which lies immediately above the proximal limit of the aneurysm and may be adherent to it. In the one case where we lacerated the renal vein, the rapid control of the structure and its partial occlusion with a Satinsky clamp permitted immediate suture repair and subsequent pursuance of the main operation.

The common iliac arteries are readily located, though, they are, on occasion displaced by the aneurysm. They may also suffer aneurysmal dilatation in which case they should be excised. The common iliac veins are closely apposed to the posterior aspect of the arteries and, to avoid their injury, it is important to stay close to the arterial wall in their dissection. Injury to the iliac veins or to the inferior vena cava can be readily controlled by pressure whilst suture repair is carried out. The ureters are readily identified as they cross the iliac arteries and are appropriately protected.

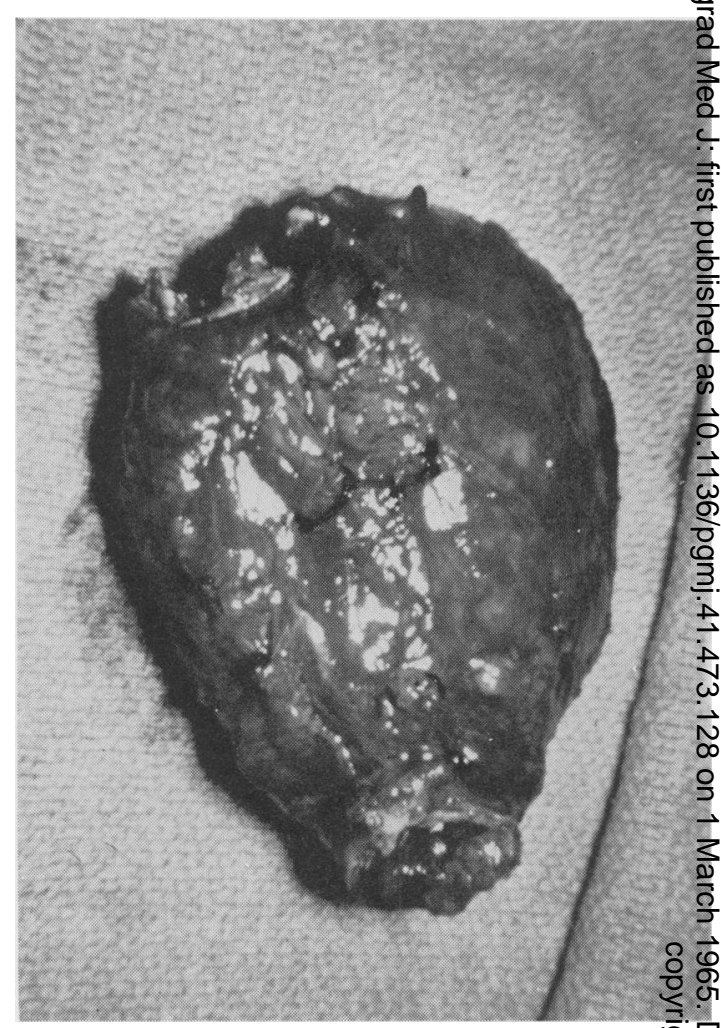

FIG. 3.-Aneurysm of abdominal aorta resecte本思 toto.

With the aorta and iliac arteries cleared, the inferior mesenteric artery is dissected out and ligated close to its origin, thereby permitting $\frac{\text { a }}{2}$ collateral circulation to the colon.

The aortic clamp is now occluded, an vascular clamps are applied to the iliac arteries $10 \mathrm{ml}$. of heparin solution are injected into each iliac artery distal to their clamps.

\section{Removal of the Aneurysm}

Although it was our initial practice to reseç the aorta with its intact aneurysm in toto (Fig. 3) we now find it easier, faster and equall effective to open the aneurysm longitudinalls evacuate its contents, dissect out the intimat aortic wall and allow the posterior portion of the lesion to remain in situ, after transfixing they open ositia of the lumbar arteries. This techw nique has the added advantage of not threaten ing the integrity of the inferior vena cava. If is important to leave an adequate cuff of about one centimeter of aortic tissue proximally to facilitate approximation of the graft. It is $v$ on occasion, necessary to endarterectomize the proximal aortic stump. 


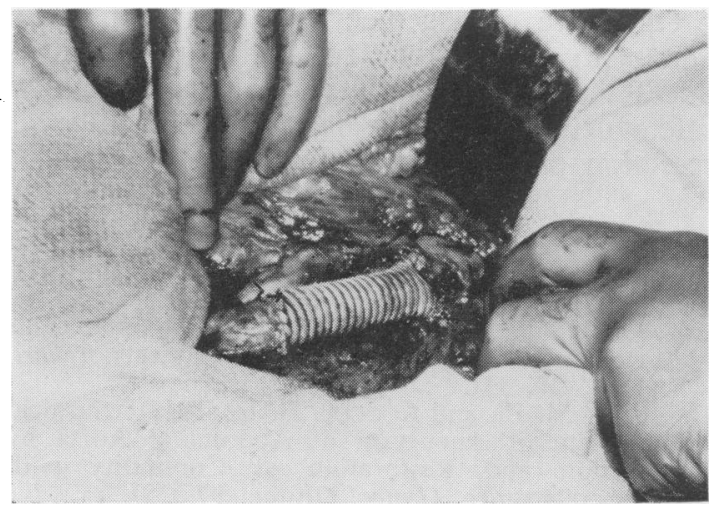

FIG. 4.-Tubular Dacron graft. Replacement after resection of aneurysm.

\section{Tailoring the Graft}

In utilizing woven crimped Dacron as the prosthesis of choice in our cases, we have found no need to preclot the grafts. It is important that the prosthesis be as near the size of the host vessel as possible and generally a proximal diameter of $22 \mathrm{~mm}$. and an iliac diameter of $11 \mathrm{~mm}$. has proved adequate. It is important to remember that restoration of aortic flow into the graft will elongate it with a resulting tortuous kinked distal limb and careful attention to this aspect of tailoring technique is most important.

\section{Proximal Anastomosis}

This is effected by a 3-0 single layer of mersilene commencing in the midline posteriorly and utilizing two atraumatic vascular needles which pass through the graft from without inwards and through the aorta from within outwards until they meet at the midaortic point anteriorly where the two ends are tied.

The proximal anastomosis is tested by clamping the graft two inches from its upper end and releasing the aortic clamp. Any leaks are reinforced by appropriately placed sutures after replacing the aortic clamp (Fig. 4).

\section{Distal Anastomosis}

Appropriate tailoring of the distal end of the tubular or bifurcation graft is carried out and before completing each iliac anastomosis, the iliac clamp should be removed to ensure that a free retrograde blood flow is present. After completion of the anastomosis on one side, the aortic clamp may be slowly released and with the blood pressure stabilized, normal perfusion

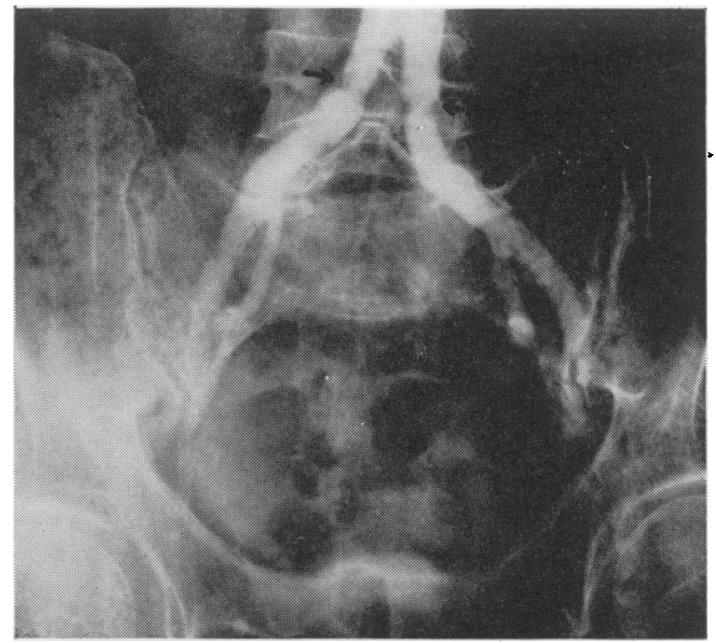

FIG. 5.-Postoperative aortogram discloses site of distal line anastomosis as a distinct 'nick' marked by arrows.

of one limb is permitted whilst clamp control of the opposite prosthetic limb provides control for the second iliac anastomosis. We have utilized a 4-0 mersilene double-needle suture technique initiated at the midpoint posteriorly and meeting at the midpoint of the vessel anteriorly where the two limbs of the sutures are tied (Fig. 5).

In the event that one or both iliac vessels are irreversibly occluded, or aneurysmal, (Fig. 6) the bifurcation graft is then anastomosed to the common femoral artery in the thigh whilst in the presence of associated occlusion of the femoral artery at the adductor canal, we have added a femoro popliteal by-pass graft to provide good peripheral arterial flow. It cannot be stressed too often that it is important to replace volumetrically all blood loss whilst the hypotensive episodes due to aortic clamp release should lead to re-occlusion of the aorta with subsequent very slow and gradual release of the clamps.

The question whether lumbar sympathetectomy should be carried out at this time is always raised, and though we have used it in the presence of concomitant advanced peripheral occlusive disease, we have not utilized it in cases of aortic resection for aneurysm where peripheral pulses are not deficient. Postoperatively, we have not made use of anticoagulants but provide a three-day course of antibiotic therapy with penicillin and streptomycin as the commonest antibiotics used. 


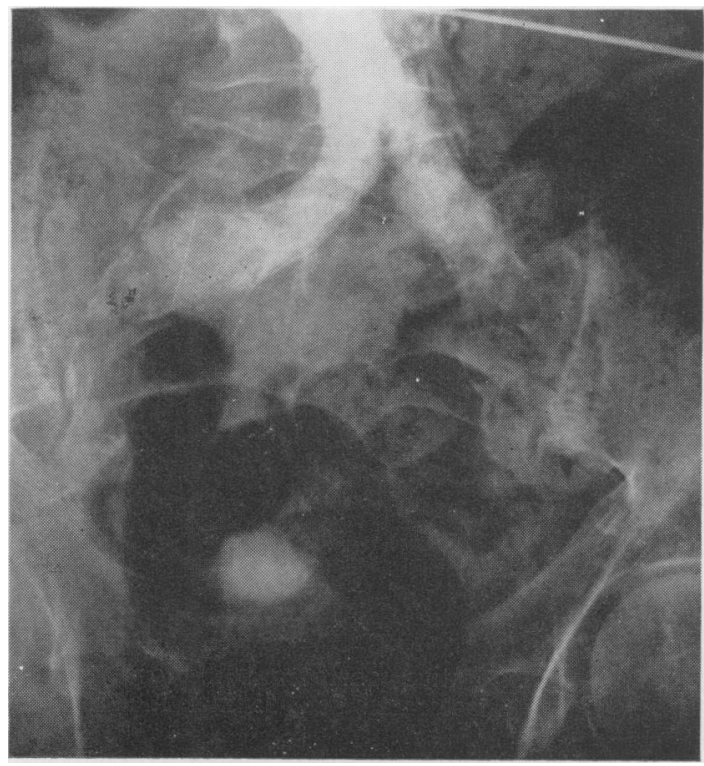

Fig. 6.-Aneurysm of aorta with concomitant aneurysmal dilation of common iliac arteries demonstrated by aortography.

\section{The Ruptured Aneurysm}

The surgical challenge imposed by a patient with a ruptured abdominal aneurysm is great indeed, and it becomes important to exert speed in attaining proximal aortic control which may, in the emergency case, be applied proximal to the renal arteries and with bleeding controlled, dissection of the infra-renal aorta and reapplication of the clamp with removal of the proximal one then becomes possible.

\section{Wound Closure}

Upon completion of the operation, the posterior peritoneum is closed by a continuous $2-0$ chromic catgut suture. The anterior abdominal wall is closed in layers using a combination of continuous chromic catgut reinforced by interrupted non-absorbable sutures of either silk or wire. We have not utilized drainage, although when considered necessary, we have used retention sutures.

\section{Summary}

A review of 14 cases with abdominal aortic aneurysms, indicates that with due care in all phases of operative management, resection of the aneurysm and replacement by a graft is a relatively safe procedure in the unruptured case with a mortality rate of less than $10 \%$ despite the advanced age of the patients.
Operative management of abdominal aortio aneurysm once it has suffered rupture intro duces technical hazards and a high mortalitक rate, further emphasizing the desirability of resection on an elective basis.

\section{REFERENCES}

BOYD, D. P., and BARTELS, C. C. (1957): Surgic臮 Treatment of Aneurysms of the Abdominal Aorta Postgrad. Med., 21, 477.

Colt, C. H. (1927): The Clinical Duration of Saccula Aortic Aneurysm in British-born Subjects, Quarto
J. Med., 20, 331.

DeBakey, M. E., and Cooley, D. E. (1953): Surgicä Treatment of Aneurysm of Abdominal Aorta by Resection and Restoration of Continuity with Homograft, Surg. Gynec. Obstet., 97, 257.

Dubost, C., Allary, M., and Oeconomos, M. (1952) $\frac{\widehat{\sigma}}{6}$ Resection of an Aneurysm of the Abdominal Aorti A.M.A. Arch. Surg., 64, 405.

EDWARDS, W. S. (1959): Progress in Synthetic Graft Development, Surgery, 45, 298.

EsteS, J. E. (1950): Abdominal Aortic Aneurysms A Study of 102 Cases, Circulation, 2, 258.

Wright, I. S., VRDAVETA, E!, and Wright, B. (1956) $\overrightarrow{\dot{n}}$ Re-opening the Case of the Abdominal Aortie Aneurysm, Circulation, 13, 754.

Aguirre Silva, R. (1942): Diverticulitis de Meckel. Perforada por Cuerpo Extrano, Arch. Soc. Cir Hosp., 12, 326.

AlHadefF, E. (1955): Perforation of Meckel's Diver ticulum by Foreign Body, Brit. J. Surg., 43, 555?

Aschan, T. (1909): A Case of Meckel's Diverticulanb Perforated by a Foreign Body, Finska Läk.-Säts Handl, 51, 118.

AsHe, P. (1961): Perforation of Meckel's Dive culum by Foreign Body, J. Irish med. Ass., 49, 3

Beale, L. (1852): Diverticulum from the Lower Part of the Ileum, Proc. Path. Soc. Lond., 3, 366.

Bernatz, P. E. (1956): Unusual Conditions Simulating Acute Appendicitis, Proc. Mayo Clin., 31, 53.

BerRy, J. A. (1927): Perforation of Meckel's Diver ticulum, Brit. J. Surg., 15, 331.

Blanc, H. H. (1899): Note Anatomo-pathologique sur Les inflammations du Diverticule de MeckeP Bull. Soc. Anat. Paris, p. 246.

BLOMQUIST, H. E. (1951): Fishbone Perforation of Meckel's Diverticulum and the Small Intestine Nord. Med., 46, 1045.

BoCK, H. (1933): Uber Meckel'sche Divertikel, ZbP Chir., 60, 1715.

CHORZEWSKI, Z. (1956): Rare Complication of Meckel's Diverticulum, Pol. Przegl. chir., 28, 1173

DenUnCe (1851): Bull. Soc. Anat. Paris, p. 369.

Donovan, E. J. (1937): Meckel's Diverticulun Perforated by a Foreign Body, Ann. Surg., 106, 953

Dowse, J. L. A. (1961): Meckel's Diverticulum Brit. J. Surg., 48, 392.

Fontaine, R., and BAUER, R. (1933): Aiguille Arreteg 52, 71.

GilletTe, W. R., and Zoltowski, P. E. (1957) N Perforation of Meckel's Diverticulum by a Foreigg Body, Amer. J. Surg., 94, 666.

HAGLER, F., and STEWART, J. W. (1920): AcutQ Perforation of Meckel's Diverticulum by a Foreign Body (Fishbone), J. Amer. med. Ass., 74, 1377. \&

HENRICHSEN, A. (1921): Ueber einen fäll von Fremkörperdivertikulitis des Meckel'schen Diverō tikels, Münch. med. Wschr., 68, 1423. 
Hiller, R. I., and BERNHARD, L. A. (1933): Gangrenous Meckel's Diverticulum Perforated by a Tomato Peel, J. Amer. med. Ass., 101, 364.

John, E. L. (1955): Perforation of Meckel's Diverticulum by a Pin, Brit. J. Surg., 43, 216.

KER, H. (1962): A Muckle of Meckel's, Lancet, i, 617.

Komarov, I. A. (1959): Perforation of Meckel's Diverticulum, Vest. Khir. Grekov., 83, 88.

LiNDQUIST, S. (1926): Perforation eines Meckel'schen Divertikels, von einem Fremdkörper Beding, $Z \mathbf{b l}$. Chir., 53, ii, 1756.

Longo, T., and BrogGI, L. (1954): Di una Singolare Complicanza di un Diverticolo di Meckel, Boll. Soc. med.-chir. Varese., 9, 256.

MacFarlane, D. A. (1948): Foreign Body Perforations in Meckel's Diverticulum, Brit. J. Surg., 35, 421.

Mastrosimone, C. (1951): Perforazione del Diverticolo di Meckel ed Ascaridiasi, Arch. Att. Soc. It. Chir., 2, 359.

MECKEL, J. F. (1812): Handbuch der pathologischen Anatomie, Vol. 1, p. 553, Leipzig.

PersSON, vON T. (1939): Meckel'sches Divertikel, durch einen Fremkörper Perforiert, Acta chir. scand., 82, 530.

Peterson, E. W. (1937): Commenting on Donovan (loc. cit), Ann. Surg., 106, 954.

PiQuand, G., and GRenet, H. (1900): Perforation d'un Diverticule Ileal par une Arete de Poisson, Bull. Soc. Anat. Paris, p. 390.

Principe, L. (1960): Perforazione da Corpo Estraneo di Diverticolo di Meckel Fibroangiomatoso, Riv. Pat. Clin., 15, 503.

Rawlinson, J. K. M. (1956): Fishbone Perforation of Meckel's Diverticulum, Brit. J. Surg., 43, 555.
Reinalda, R. (1958): A Case of Meckel's Diverticulum Perforated by a Fishbone, Geneesk. Gids., 36, 383.

Roessel, C. W. (1962): Perforation of Meckel's Diverticulum by a Foreign Body; Case Report and Review of the Literature, Ann. Surg., 156, 972.

Rossman, J. I. (1943): Fishbone Perforation of Meckel's Diverticulum, Canad. med. Ass. J., 49, 48.

Rumore, A. (1958): Perforation of Meckel's Diverticulum by Grape Seeds, Med. J. Aust., 45, 110.

RuYsch, F. (1701): Thesaurus Anatomicus, Vol. 7, fig. 283.

SCHWENK, C., and Pollnow, M. (1912): Fremdkörper im Meckel'schen Divertikel unter den Erscheinungen der Appendicitis, Berl. klin. Wschr., 49, 2228.

SEIBERT, F. M. (1950): Seltene Erkrankingsformd des Meckel'schen Divertikel. Fremdkörperperforation ohne Begleitdiverticulitis, Artzl. Wschr., 550, 1023.

Tamraz, J. M. (1940): Case of Acute Gangrenous Diverticulitis (Meckels) with Perforation due to a Fishbone, Milit. Surg., 87, 328.

WALKLING: cited by Webb (q.v.).

WARD-MCQuaId, J. N. (1950): Perforated Meckel's Diverticulum by Tomato Skin, Lancet, i, 349.

WebB, R. C. (1933): Meckel's Diverticulum Perforated by a Fishbone, Ann. Surg., 98, 159.

Weinstein, V. A. (1942): Fishbone Perforation of Meckel's Diverticulum, J. Mt. Sinai Hosp., 9, 29.

WHELAN, P. J. (1951): Fishbone Perforation of Meckel's Diverticulum, Canad. med. Ass. J., 64, 67.

Wilcox, A. E. (1932): Case Report in Minn. Med., 15, 558.

Williams, R. V. (1940): Perforation of Meckel's Diverticulum by a Fishbone, Minn. Med., 23, 44. 